\title{
STUDI PERENCANAAN JEMBATAN CUMPLENG DENGAN METODE PRATEKAN DI KEC. SLAHUNG KABUPATEN PONOROGO
}

\author{
Adi Susanto ${ }^{* 1}$, Yosef Cahyo S.P. ${ }^{2}$, Sigit Winarto ${ }^{3}$ \\ 1,2,3 Fakultas Teknik, Universitas Kadiri. \\ e-mail : ${ }^{* 1}$ adi.aira1002@gmail.com ${ }^{2}$ yosef.cs@unik-kediri.ac.id, ${ }^{3}$ sigit.winarto@unik- \\ kediri.ac.id
}

\begin{abstract}
In planning the Cumpleng Bridge in Slahung Sub-district, Ponorogo Regency with an overall span of 30 meters, the overall width of the bridge is 4.20 meters and the width of the pavement is 3.50 meters. Given the Cumpleng Bridge is one of several bridges in the Slahung District development project environment. This bridge has an important meaning as a link between Slahung Village and Galak Village, so it is expected to facilitate the flow of traffic and improve economic development and development in the area. In this planning study we use a prestressed method to calculate the calculation of the backrest and backrest poles, vehicle flooring, main girders and abutments / underbuildings. The results of this bridge planning include: planning the backrest, vehicle floor, main beam and transverse beam. Main beam using composite prestressed concrete post-tensioning method (post-tensioning with height, 1.10 meters, concrete quality $(f c) 40 \mathrm{MPa}$, consisting of 2 tendons used type VSL type 12 with as many as 10 strand cables and other buildings using concrete regular boned).
\end{abstract}

Keywords : Concrete, Stress, Pressure and Cross section, Bridge

\begin{abstract}
Abstrak
Dalam perencanaan Jembatan Cumpleng di Kecamatan Slahung Kabupaten Ponorogo dengan bentang keseluruhan 30 meter, lebar keseluruhan jembatan 4,20 meter dan lebar perkerasan 3,50 meter. Mengingat Jembatan Cumpleng merupakan salah satu dari beberapa jembatan yang ada di lingkungan proyek pengembangan wilayah Kecamatan Slahung. Jembatan ini mempunyai arti yang penting sebagai penghubung antara Desa Slahung dan Desa Galak, sehingga diharapkan dapat memperlancar arus lalu lintas serta meningkatkan perkembangan perekonomian dan pembangunan di daerah. Pada studi perencanaan ini kami menggunakan metode pratekan untuk menghitung perhitungan sandaran dan tiang sandaran, lantai kendaraan, gelagar induk dan abutment/bangunan bawah. Hasil dari perencanaan jembatan ini meliputi : perencanaan tiang sandaran, lantai kendaraan, balok induk dan balok melintang. Balok induk menggunakan beton pratekan komposit metode pasca tarik (post-tensioning dengan tinggi, 1,10 meter, mutu beton $\left(f_{c}\right) 40$ Mpa, terdiri 2 buah tendon dipakai jenis VSL tipe 12 dengan kabel untaian sebanyak 10 buah dan bangunan yang lain menggunakan beton bertulang biasa).
\end{abstract}

Kata Kunci : Beton, Tegangan, Pratekan Dan Penampang, Jembatan 


\subsection{Latar Belakang}

\section{PENDAHULUAN}

Dalam proses pemerataan pembangunan keseluruhan wilayah negara Indonesia, maka perlu ditindak lanjuti dan ditingkatkan pembangunan daerah, pembangunan pedesaan dan pembangunan perkotaan [1][2][3]. Untuk menunjang proses itu diperlukan adanya suatu sarana yang merupakan sarana penting bagi perkembangan ekonomi dewasa ini [4][5][6]. Pembangunan perhubungan diarahkan untuk lebih memperlancar arus barang dan jasa serta meningkatkan mobilitas manusia. Dan memperhatikan kebutuhan masyarakat akan sutau sarana perhubungan darat, baik jalan maupun jembatan[7]. Secara umum jembatan dapat diartikan sebagai suatu konstruksi yang dibangun untuk transportasi yang menghubungkan antara daerah satu dengan daerah yang lainnya, karena terputus akibat adanya sungai, waduk dan lembah pada persimpangan jalan.

\subsection{Identifikasi Masalah}

Jembatan Cumpleng merupakan salah satu dari beberapa jembatan yang ada di lingkungan proyek pengembangan wilayah Kecamatan Slahung. Jembatan ini mempunyai arti yang penting sebagai penghubung antara Desa Galak dan Desa Slahung, sehingga diharapkan dapat memperlancar arus lalu lintas serta meningkatkan perkembangan perekonomian dan pembangunan di daerah.

Adapun alasan pemakaian konstruksi beton dengan metode pratekan, antara lain :

a. Proses perencanaan pemasangan gelagar utama jembatan relatif lebih cepat

b. Mutu kuat betonnya dijamin memenuhi standart karena pabrikasi

c. Pelaksanaannya mudah dirakit di lapangan sehingga lebih cepat dan praktis

d. Mampu menahan kuat tekan yang tinggi sehingga dapat digunakan untuk menahan arus beban lalu lintas yang lebih besar.

Akan tetapi metode pratekan ini memerlukan pengawasan dan penelitian yang cukup tinggi dalam hal pekerjaan penarikan tendon, pemancangan tiang pancang beton pada pondasi dan biaya pemeliharaan yang relatif cukup mahal. Untuk itu diperlukan perencanaan yang lebih baik dan aman dari segi stabilitas bangunan sehingga jembatan yang direncanakan dapat bermanfaat seperti yang diharapkan.

\section{METODE PENELITIAN}

\subsection{Definisi Jembatan}

Menurut wikipedia bahasa indonesia jembatan merupakan struktur yang dibuat untuk menyebrangi jurang atau rintangan seperti sungai, rel kereta api ataupun jalan raya. Jembatan juga merupakan bagian dari infrastruktur transportasi darat yang sangat vital dalam aliran 
perjalanan[8][9][10]. Sedangkan menurut Struyk dan Veen jembatan adalah suatu konstruksi yang gunanya untuk meneruskan jalan melelui rintangan yang berada lebih rendah. Rintangan ini biasanya jalan lain(jalan air atau jalan lalu lintas biasa)[11].

Selanjutnya menurut Supriyadi dan Muntohar jembatan adalah suatu bangunan yang memungkinkan suatu jalan menyilang sungai/saluran air, lembah atau menyilang jalan lain yang tidak sama tinggi permukaannya. Secara umum suatu jembatan berfungsi untuk melayani arus lalu lintas dengan baik, dalam perencanaan dan perancangan jembatan sebaiknya mempertimbangkan fungsi kebutuhan transportasi, persyaratan teknis dan estetika-arsitektural yang meliputi : Aspek lalu lintas, Aspek teknis, Aspek estetika[3][12].

\subsection{Beton Pratekan}

Beton pratekan pada dasarnya adalah beton yang mengalami tegangan - tegangan internal dengan besar dan distribusi sedemikian rupa sehingga dapat mengimbangi sampai batas - batas tertentu tegangan - tegangan yang terjadi akibat beban luar[13]. Seperti pada beton bertulang biasa, dimana beton pratekan dapat juga merupakan suatu struktur komposit antara dua bahan dengan mutu yang berbeda yang menggunakan bahan bermutu tinggi. Dua bahan tersebut adalah baja dan beton, dimana baja dipakai sebagai tendon atau kabel yang dikelompokkan menjadi satu kesatuan. Seperti diketahui beton tidak kuat untuk menahan atau menerima tarikan yang cukup besar, tegangan tarikan selalu terjadi pada struktur yang besar atau mempunyai bahan yang cukup besar[5][14]. Dengan adanya pertimbangan tersebut, maka daerah yang diperkirakan akan timbul tegangan tarik dipasangkan kabel atau tendon yang harus diberikan tegangan awal. Pada beton pratekan juga dipakai tulangan biasa pada penampang yang diberi gaya pratekan, hal ini dimaksudkan supaya struktur tidak mengalami keruntuhan mendadak setelah retak. Arah tulangan ini adalah memanjang dan melintang[15].

\subsection{Acuan Perencanaan}

Perencanaan, Pedoman yang digunakan menggunakan literatur buku-buku dan tata cara perencanaan untuk jalan raya dan jembatan[16].

\subsection{Peraturan Perencanaan}

Jika kita merencanakan suatu bangunan sudah tentu kita harus memperhatikan segala aspek yang berhubungan dengan bangunan tersebut, dan harus sesuai dengan pemahaman isi buku-buku yang ada[17].

\subsection{Peraturan Perhitungan Konstruksi}

Peraturan perhitungan kontruksi antara lain, Peraturan Perencanaan Pembebanan untuk Jalan Raya dan Jembatan[18]. 


\subsection{Dasar Perhitungan Konstruksi}

Dasar perhitungannya yaitu Konstruksi diperhitungkan terhadap pembebanan perhitungan konstruksi antara lain, peraturan perencanaan pembebanan untuk Jalan Raya dan Jembatan serta sesuai dengan pedoman literatur buku - buku.

\subsection{Spesifikasi Teknik}

Spesifikasi Tekniknya meliputi fc' $=40 \mathrm{MPa}, \mathrm{fc}^{\prime}=22,5 \mathrm{MPa}$ dan fy $=240 \mathrm{MPa}[19]$

\subsection{Tuntutan dan Ketentuan Umum Perencanaan}

Perencanaan Jembatan harus kita perhatikan antara lain, Kontruksi harus aman, kokoh, kuat dan biaya perencanaan bangunan kontruksi harus hemat dan efisien dengan catatan tidak boleh mengurangi kekuatan konstruksi, agar tidak membahayakan bangunan dan keselamatan penggunaan bangunan tersebut[20].

\subsection{Pembebanan}

Dalam perencanaan struktur atas perlu memperhatikan beban yang terjadi pada konstruksi bangunan antara lain Peraturan pembebanan, peraturan perencanaan pembebanan untuk Jalan Raya dan Jembatan[21].

\subsection{Macam Pembebanan}

Secara garis besar beban yang bekerja pada jembatan dapat dibagi sebagai berikut:

\subsubsection{Beban Primer}

Beban primer adalah beban yang merupakan beban utama dalam perhitungan tegangan untuk merencanakan jembatan. Yang termasuk beban primer adalah : Beban Mati, Beban hidup, Beban pada Trotoir, Kerb dan Sandaran dan Koefisien Kejut[22].

\subsubsection{Beban Sekunder}

Beban sekunder ialah beban yang merupakan beban sementara yang selalu diperhitungkan tegangan pada setiap perencanaan jembatan, dalam hal ini yang termasuk beban sekunder adalah sebagai berikut : Beban Angin, Gaya Rem dan Traksi, Gaya Akibat Gempa Bumi, Gaya Akibat Gesekan Pada Tumpuan Bergerak, Pembagian Klas Muatan Jembatan dan Muatan Kombinasi. 
2.12 Metodologi Perencanaan

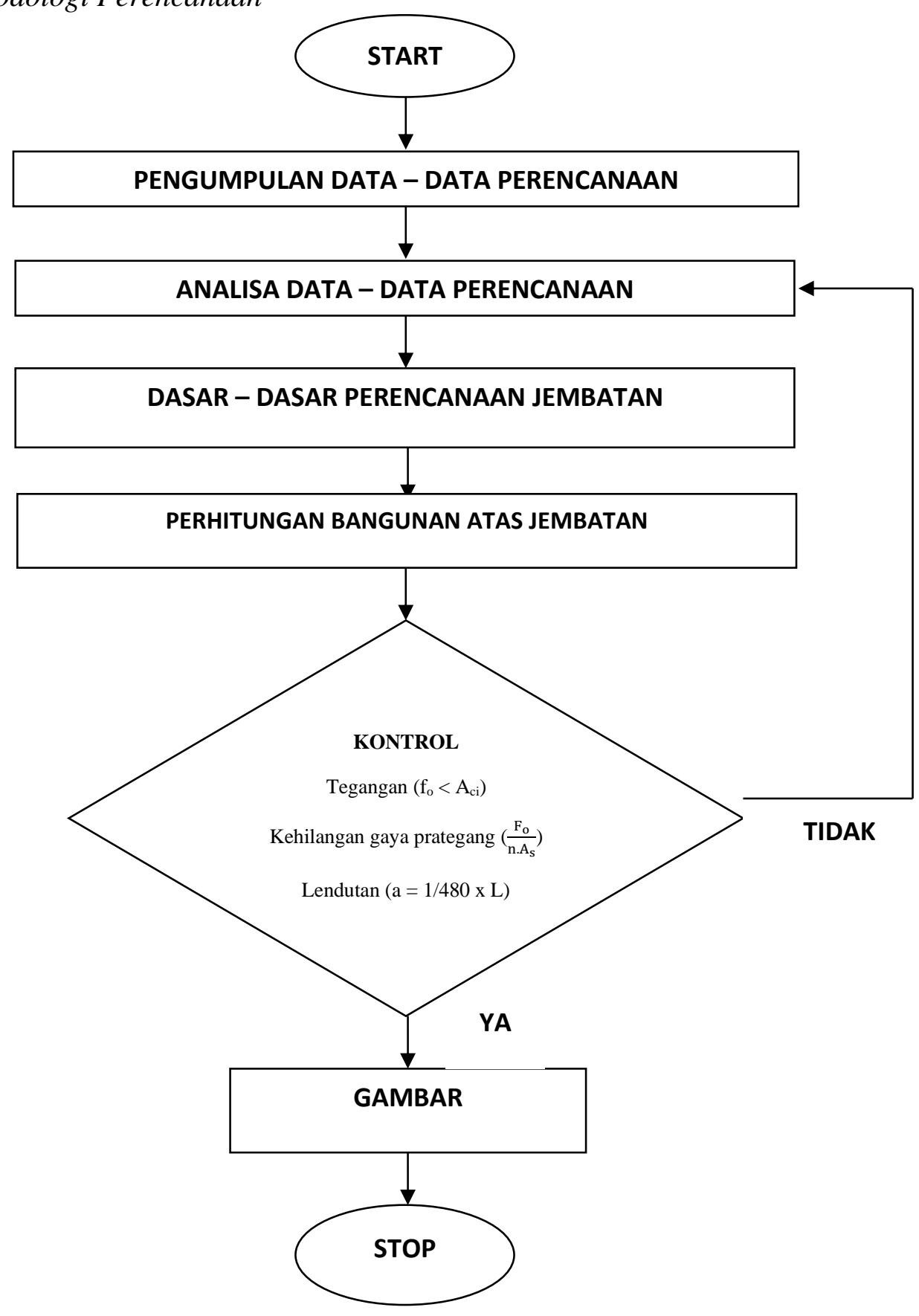




\section{HASIL DAN PEMBAHASAN}

\subsection{Data-data Perencanaan}

A. Data Struktur

Data struktur merupakan data perencanaan jembatan yang akan dikerjakan.

B. Data Pembebanan

Data pembebanan merupakan data-data beban yang bekerja pada jembatan.

C. Perhitungan Dimensi dan Jumlah Balok Gelagar

$\mathrm{L}=30,60 \mathrm{~m}$ dengan menggunakan 5 balok gelagar.

D. Pembebanan Lantai Jembatan dan Trotoar

Pembebanan Lantai Jembatan

a) Beban mati

$$
\begin{array}{lll}
\text { B.s Plat } & =0,20 \times 1 \times 2400 \times 1,3 & =624 \mathrm{Kg} / \mathrm{m} \\
\text { B.lapisan aspal } & =0,05 \times 1 \times 2240 \times 1,3 & =145,6 \mathrm{Kg} / \mathrm{m} \\
\text { B.air hujan } & =0,05 \times 1 \times 1000 \times 2,0 & =100 \quad \mathrm{Kg} / \mathrm{m} \\
\text { q1 } & & =869,6 \mathrm{Kg} / \mathrm{m}
\end{array}
$$

b) Beban hidup

$$
\text { Pult }=1,8 \times 14625=26325 \mathrm{Kg} \text {. }
$$

c) Pembebanan Trotoar

q2

$$
=869,6 \mathrm{~kg} / \mathrm{m}
$$

Pembebanan Sandaran

a) Berat pipa

$$
2,00 \times 6,6 \times 1,00 \times 1, \quad=14,520 \mathrm{Kg} / \mathrm{m}
$$

b) Berat tiang

$$
\begin{array}{ll}
0,15 \times 0,15 \times 24 \times 1 \times 1,3 & =70,20 \mathrm{Kg} / \mathrm{m} \\
\text { q3 } & =84,72 \mathrm{Kg} / \mathrm{m} \\
\mathrm{q} 4=\mathrm{q} 2+\mathrm{q} 3=(869,6+84,720) & =954,32 \mathrm{Kg} / \mathrm{m}
\end{array}
$$

c) Beban hidup

$$
\mathrm{q} 5=500 \times 1 \quad=500,00 \mathrm{Kg} / \mathrm{m}
$$

Perhitungan Statika Plat Lantai Kendaraan

$$
\begin{aligned}
\mathrm{d}=\mathrm{h}-1 / 2 \emptyset-\text { tebal selimut beton } & \\
=200-(1 / 2 \times 14)-20 & =173 \mathrm{~mm} \\
\mathrm{~b}=0,5 \times 1750 \mathrm{~mm} & =875 \mathrm{~mm} \\
(\mathrm{SK}-\mathrm{SNI}-\mathrm{T} 15-1991)=0,5 \times 869,6 \times 1,002 & =434,8 \mathrm{Kg} \cdot \mathrm{m} \\
\mathrm{P}=\text { beban roda }(\mathrm{kN}) & =26325 \mathrm{KN}
\end{aligned}
$$


E. Penulangan Plat Lantai Kendaraan Arah Melintang (Y)

a) Penulangan pada tumpuan

$$
\begin{aligned}
\mathrm{Mu}=434,8+4949,1 \quad & =5383,9 \mathrm{~kg} \cdot \mathrm{m} \\
& =14,118 \mathrm{Mpa}
\end{aligned}
$$

Dipakai tulangan tarik D $14-100$

Dipakai tulangan tekan D 14-250

ISSN 2337-7720

; As $=1539 \mathrm{~mm}$

; As $=616 \mathrm{~mm}$

(Kusuma.G \& Vis: 1994, 82).

b) Penulangan pada lapangan

Dipakai tulangan tekan D 14-250; As $=616 \mathrm{~mm}^{2}$

Beban Mati Jembatan kelas II adalah $=7,00$ Ton.

Beban hidup lantai kendaraan yang ditimbulkan sebesar

$1,6 \times 70,00$ $=112,000 \mathrm{kN}$.

Momen yang ditimbulkan sebesar

$\mathrm{Mt}=39.401 \mathrm{kNm}>\mathrm{M}_{\mathrm{u}}$ $=34,233 \mathrm{kNm} \quad($ Aman....! $)$

Kontrol Momen Nominal

$\mathrm{M}_{\mathrm{n}} \phi=2920.476>\mathrm{M}_{\mathrm{u}}$ $=2052.325 \mathrm{kNm}($ Aman....! $)$

Lendutan yang terjadi pada balok pratekan adalah

$6,77 \mathrm{~mm}<50,63 \mathrm{~mm}$

(Aman....!)

Dimensi Balok diafragma 20/50 dengan tulangan pokok $8 \varnothing 14$ dan sengkang $\varnothing 8-150$

\section{KESIMPULAN}

Dari hasil perhitungan, maka dapat diambil kesimpulan sebagai berikut :

1. Dalam perencanaan pembangunan jembatan Cumpleng ini dipakai beton pratekan komposit menggunakan metode pasca tarik (post tensioning), dengan bentang jembatan 30 meter, tinggi balok pratekan 1,00 meter dan jumlah balok adalah 10 (sepuluh) buah dengan jarak masing - masing 1,50 meter, dengan jumlah kabel (tendon) adalah 2 (dua) buah. Dari hasil perhitungan berdasarkan perhitungan statika yang ada maka dapat diambil kesimpulan bahwa momen yang ditimbulkan sebesar $\mathrm{Mt}=39.401 \mathrm{kNm}>\mathrm{M}_{\mathrm{u}}=$ $34,233 \mathrm{kNm}(\operatorname{aman} . . . !)$

2. Sedangkan pembebanan yang ditimbulkan pada lantai kendaraan untuk jembatan kelas II digunakan muatan hidup 70\% dari beban T sebesar : $70 \%$ x 10 ton $=7$ ton $=70 \mathrm{kN}$ 
dengan jarak as 1,75 meter. Sehingga beban hidup lantai kendaraan yang ditimbulkan sebesar $1,6 \times 70,00=112,000 \mathrm{kN}$.

3. Setelah dihitung dapat ditentukan desain yang digunakan untuk gelagar induk yaitu : Lendutan yang terjadi pada balok pratekan adalah $6,77 \mathrm{~mm}$, sangat kecil bila dibandingkan dengan lendutan yang diijinkan yaitu $50,63 \mathrm{~mm}$, ini disebabkan akibat perlawanan dari gaya prategang yang menghasilkan lendutan ke atas.

4. Penempatan kabel pada balok prategang dipilih bentuk parabola, hal ini disesuaikan dengan momen yang terjadi akibat beban merata yaitu berbentuk parabola. Daerah aman kabel adalah daerah pada penampang memanjang balok pratekan, bilamana kabel akan diletakkan pada daerah tersebut tidak akan terjadi tegangan tarik diserat atas maupun diserat bawah. Pada saat pembebanan gaya pratekan awal (Fo). Akibat adanya daerah aman kabel maka batas bawah kedudukan kabel bergeser sebesar $=6,83 \mathrm{~cm}$ (Penampang tumpuan sebelum komposit) dan 5,58 cm (Penampang lapangan sebelum komposit). Dan pada saat pemberian gaya pratekan efektif (F) pada serat atas masih diperkenankan terjadinya tegangan tarik sebesar : 16,27 (Penampang tumpuan sesudah komposit) dan 18,21 cm (Penampang lapangan sesudah komposit)

5. Balok diafragma setelah dihitung menggunakan dimensi 20/50 dengan tulangan :

- Tulangan tarik $4 \varnothing 14$

- Tulangan tekan $4 \varnothing 14$

- Tulangan sengkang $\varnothing 8-150$

\section{SARAN}

1. Dalam merencanakan suatu jembatan sangat terkait dengan berbagai disiplin ilmu diantaranya konstruksi beton, konstruksi baja, mekanika tanah, hidrologi dan sebagainya, sehingga bagi para perencana sangat dituntut dalam penguasaan berbagai macam ilmu tersebut.

2. Pada pelaksanaan harus benar - benar menggunakan mutu beton dan baja yang tinggi dengan pengawasan yang teliti, sehingga jembatan yang dibangun sesuai dengan hasil perencanaan dari segi konstruksi maupun ekonomi.

\section{UCAPAN TERIMAKASIH}

Dalam penyusunan artikel ini, penulis ucapkan terimakasih kepada dosen pembimbing dan Universitas Kadiri. Penulis berharap agar artikel ini dapat bermanfaat bagi pembaca. 


\section{DAFTAR PUSTAKA}

[1] A. I. Candra, "Analisis Daya Dukung Pondasi Strauss Pile pada Pembangunan Gedung Mini Hospital Universitas Kadiri,” Ukarst, vol. 1, no. 1, pp. 63-70, 2017.

[2] R. Suryanita, Z. Djauhari, and A. Wijaya, "Respons Struktur Jembatan Beton Prategang Berdasarkan Spektrum Gempa Wilayah Sumatera,” J. Sains dan Teknol., vol. 15, no. 1, pp. 18-24, 2016.

[3] B. Leksono, "STUDI PERENCANAAN JEMBATAN BETON PRATEKAN," Wahana Tek., vol. 1, no. 1, 2012.

[4] P. A. Y. NOOR, "STUDI PERENCANAAN STRUKTUR JEMBATAN BETON BOX GIRDER PRATEGANG SEGMENTAL DENGAN METODE KESETIMBANGAN BEBAN (LOAD BALANCING).” University of Muhammadiyah Malang, 2016.

[5] T. D. Herlambang, "Perencanaan Jembatan Upper Structure Beton Prategang Di Desa Popoh Kabupaten BlitarABSTRAK Dewa H, Tessar A. 2013. Perencanaan Jembatan Upper Structure Beton Prategang Di Desa Popoh Kabupaten Blitar. Proyek Akhir, Program Studi D3 Teknik Sipil Dan Banguna," Tugas Akhir Jur. Tek. BangunanFakultas Tek. UM, 2015.

[6] A. Nabila, "Modifikasi perencanaan jembatan THP Kenjeran menggunakan struktur Concrete Box Girder Pratekan.” Institut Teknologi Sepuluh Nopember, 2017.

[7] D. P. Umum, "Pedoman Perencanaan Pembebanan Jembatan Jalan Raya," Yayasan Badan Penerbit PU, Jakarta, 1987.

[8] Y. Okta Florinsia, "Studi Perencanaan Struktur Atas Jembatan Baru Kali Manyar Kabupaten Gresik Menggunakan Beton Pratekan,” 2016.

[9] T. Y. Purnomo, L. D. Krisnawati, and Y. C. S. Purnomo, "Kajian Jembatan Kecamatan Sendang (Ruas Jalan Tugu-Pabyongan) Kabupaten Tulungagung dengan Metode Komposit,” J. Manaj. Teknol. Tek. Sipil, vol. 1, no. 1, pp. 112-125, 2018, doi: 10.30737/jurmateks.v1i1.145.

[10] F. Febriantoro, Y. C. S. Purnomo, and A. Ridwan, "Study Perencanaan Pondasi Tiang Pancang Jembatan Sembayat Baru II Kecamatan Manyar Kabupaten Gresik,” J. Manaj. Teknol. Tek. Sipil, vol. 1, no. 1, pp. 148-159, 2018, doi: 10.30737/jurmateks.v1i1.147.

[11] E. Soewartono, "STUDI PERENCANAAN BANGUNAN ATAS JEMBATAN MENTIKAN DI KOTA MOJOKERTO DENGAN MENGGUNAKAN METODE 
KOMPOSIT,” MAJAPAHIT TECHNO J. Ilm. dan Teknol., vol. 4, no. 2, pp. 53-59, 2017.

[12] B. A. Tomigolung, D. M. Rondonuwu, and O. Rogi, "Penataan Ruang Kawasan Tepi Sungai Tondano Di Segmen Kampung Tubir Sampai Jembatan Miangas Di Manado,” SPASIAL, vol. 5, no. 1, pp. 32-45, 2018.

[13] I. G. P. Joni, "STUDI PERENCANAAN JEMBATAN BETON TIPE STRUKTUR PLAT MENERUS DENGAN TULANGAN DUA ARAH," J. Ilm. Tek. Sipil Vol, vol. 18 , no. $1,2014$.

[14] M. F. Ramadianto and Q. Sugeng Riyanto, "PERENCANAAN JEMBATAN PENYEBERANGAN ORANG DENGAN STRUKTUR BAJA CASTELLATED DAN STRUKTUR BETON PRATEGANG VOIDED SLAB (Studi kasus Kawasan Industri Rembang Pasuruan Jl. Raya Surabaya-Pasuruan Km 50, Raci, Pasuruan),” Prokons J. Tek. Sipil, vol. 8, no. 2, pp. 124-133, 2014.

[15] S. N. Indonesia, "Tata Cara Perhitungan Struktur Beton untuk Bangunan Gedung," Badan Stand. Nasional, Puslitbang pemukiman, Bandung, 2002.

[16] B. S. Nasional, "Tata cara perhitungan harga satuan pekerjaan beton pracetak untuk konstruksi bangunan gedung," Jakarta Badan Standarisasi Nas., 2012.

[17] H. Frick, Mekanika Teknik 2, Statika dan Kegunaannya. Kanisius, 1979.

[18] W. Hadi Pratomo, "Struktur Beton Prategang (Teori dan Prinsip Desain)," Nova, 1994.

[19] A. I. Manu, "Dasar-Dasar Perencanaan Jembatan Beton Bertulang," PT Mediat. Saptakarya, DPU, 1995.

[20] C.-K. Wang, B. Hariandja, and C. G. Salmon, Desain beton bertulang. Erlangga, Jakarta, 1987.

[21] C.-K. Wang, C. G. Salmon, and B. Hariandja, "Desain Beton Bertulang Jilid 1," Jakarta: Erlangga, 1990.

[22] L. Z. Ilmi, "Studi Perencanaan Struktur Atas Jembatan Grobogan Lumajang (Km SBY 132+ 240) dengan Sistem Cable Stayed,” 2016. 